\title{
International Journal of
}

\section{Computer Network and Information Security}

\section{Kol.10}

No. 12 Dec. 2018

\section{IJCNIS Kol.10} Http:// www.mecs-press .org Vol. 10 No.12 December 2018
Modern Education

and Computer Science PRESS 
International Journal of Computer Network and Information Security (IJCNIS)

ISSN Print: 2074-9090, ISSN Online: 2074-9104

Volume 10, Number 12, December 2018

\section{Contents}

\section{REGULAR PAPERS}

An Email Modelling Approach for Neural Network Spam Filtering to Improve Score-based Anti-spam 1 Systems Yahya Alamlahi, Abdulrahman Muthana

An Integrated Perceptron Kernel Classifier for Intrusion Detection System

Ruby Sharma, Sandeep Chaurasia

Security Risk Analysis and Management in mobile wallet transaction: A Case study of Pagatech Nigeria

Limited

Musbau D. Abdulrahaman, John K. Alhassan, Joseph A. Ojeniyi, Shafii M. Abdulhamid

A Novel Infrared (IR) Based Sensor System for Human Presence Detection in Targeted Locations

Kakelli Anil Kumar, Omkar Dhadge

Performance Analysis of Underwater Acoustic Communication using IDMA-OFDM-MIMO with Reed

Solomon and Turbo Code

Rajashri Khanai, Salma S. Shahapur, Dattaprasad Torse

Underwater Sensor Networks: An Efficient Node Deployment Technique for Enhancing Coverage and 